\title{
THE LIGHTWEIGHT TEXTILE REINFORCED CONCRETE FOR THIN-WALLED STRUCTURES
}

\author{
Tereza Cibulka*, Luboš Musil, Jan VodičKa \\ Czech Technical University in Prague, Faculty of Civil Engineering, Department of Concrete and Masonry \\ Structures, Thákurova 7, 16629 Prague, Czech Republic \\ * corresponding author: tereza.cibulka@fsv.cvut.cz
}

Abstract. The article deals with lightweight concrete with non-conventional reinforcement and its application in thin-walled structures. As part of experimental research, several sets of thin-walled slab and complementary specimen were made to determine the material characteristics of lightweight concrete. The porous aggregate Liapor was used in the recipe. Two-dimensional carbon and 3D glass textiles were used as reinforcement. The impact study of different casting technologies and recipe on the material characteristics of lightweight concrete was included in the research. Fresh concrete for the slab production was placed in special wooden molds. The slabs were concreted in vertical and horizontal position. The casting method has a significant impact on the element material characteristics. Reinforced specimens have shown high strength, even in thin-walled structures with low bulk density.

KEYWORDS: Lightweight concrete, lightweight aggregate, fibre reinforced concrete, textile reinforced concrete.

\section{INTRODUCTION}

At present, the demand for concrete with special characteristics is growing. Not only physical-mechanical but also aesthetical characteristics are desired. An emphasis is placed on low overall costs together with high load bearing capacity demand.

One of the criteria is the requirement to reduce the weight of the structure itself. Concrete composite with classified low bulk density is called lightweight concrete (LC). The structure can be efficiently lightened by reducing the concrete matrix weight itself. This can be realized by partial or full replacement of the natural aggregate by a porous aggregate. [1]

Special reinforcement methods, as compared with standard concrete reinforcement, offer an interesting alternative in making complex and thinner structures with a high load bearing capacity. When the fibres are fixed in a textile mesh, this lightweight concrete is called the textile reinforced lightweight concrete (TRLC).

Research on LC with special reinforcement, which takes place at the Faculty of Civil Engineering of the CTU in Prague, deals with the possibilities of applications, technologies and material characteristics of TRLC. Thin-walled structures are one of the suitable applications. The experimental verification of hypothesis is an important part of the research. The ongoing initial experiments are focused on production of interior furniture. The next step is an application of TRLC in street furniture.

\subsection{Lightweight CONCRETE (LC)}

Lightweight concrete is classified as a concrete with a dry bulk density of more than $800 \mathrm{~kg} / \mathrm{m}^{3}$ and less than $2,000 \mathrm{~kg} / \mathrm{m}^{3}$. Porous aggregates, such as ceramsite

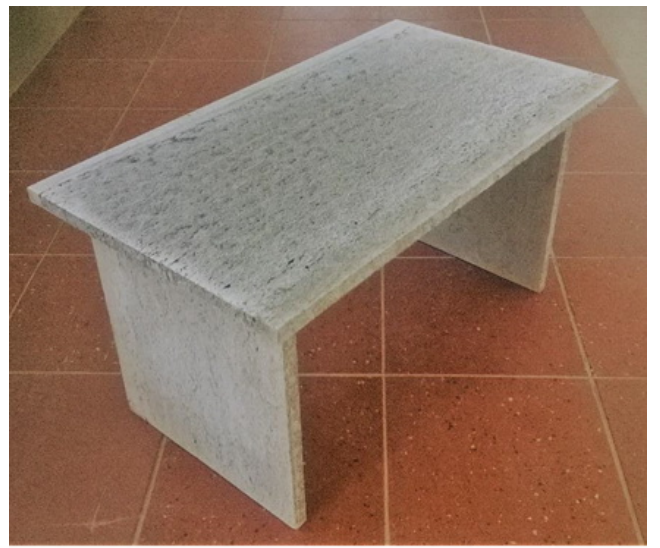

Figure 1. The coffee table 3 .

(Liapor) or expanded perlite, are used as replacements for natural aggregates. Porous stone, brick gravel, expanded vermiculite or other filler material can also replace natural aggregates. [1]

Because the concrete modulus of elasticity is directly related to the modulus of elasticity of the used aggregate, LC has lower static elastic modulus values. [2] The concrete strength is mainly determined by the strength of used cement binder, since the porous aggregate strength is usually lower than the strength of the cement stone. Lower thermal expansion of LC has a positive effect on cracking. However, due to lower stiffness, lightweight concrete is prone to deformation, such as creep and shrinkage.

\subsection{Textile Reinforced Lightweight Concrete (TRLC)}

The reinforcing fibres of textile reinforced concrete (TRC) are evenly distributed in a flat (2D) or spatial 

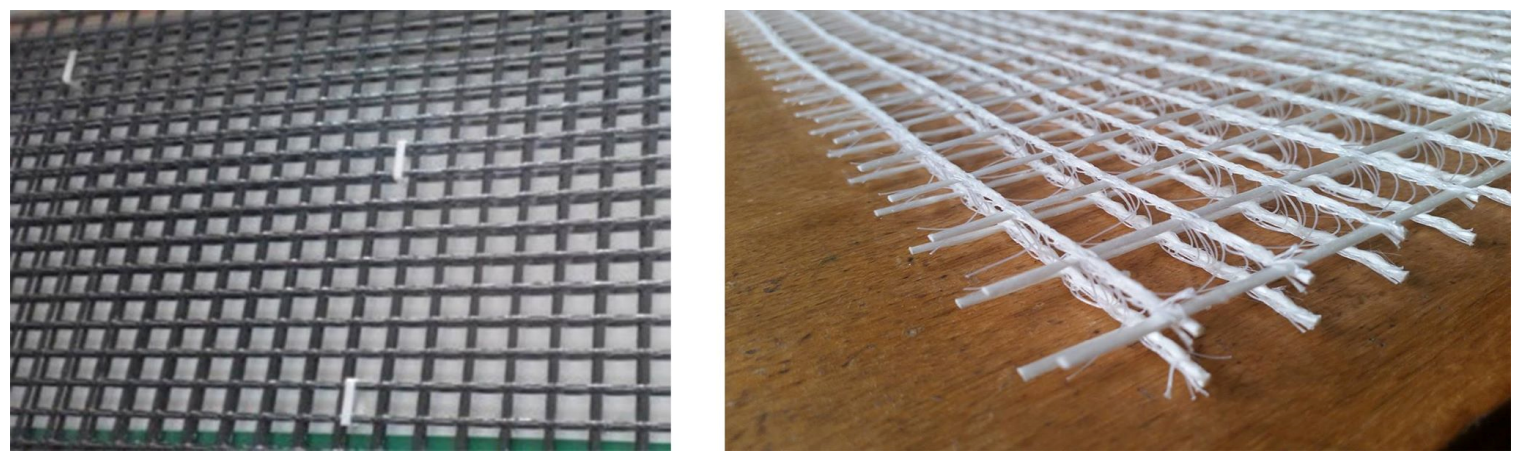

Figure 2. 2D carbon and 3D glass textiles.

\begin{tabular}{|c|c|c|c|c|c|}
\hline \multicolumn{3}{|c|}{ SPECIMENS } & \multirow{2}{*}{ REINFORCEMENT } & \multirow{2}{*}{ FORMWORK } & \multirow{2}{*}{ PIECES } \\
\hline SET & & DIMENSIONS [mm] & & & \\
\hline \multirow{4}{*}{ TRLC } & \multirow{2}{*}{1} & \multirow{2}{*}{$700 / 425 / 25$} & unreinforced & vertical & 1 \\
\hline & & & \multirow{2}{*}{ 2D carbon textile } & vertical & 2 \\
\hline & 2 & $700 / 425 / 20$ & & vertical & 2 \\
\hline & 3 & $700 / 400 / 18$ & $3 \mathrm{D}$ glass textile & vertical & 1 \\
\hline
\end{tabular}

TABLE 1. Overview table of slab specimens.

(3D) mesh and are placed in a suitable position relative to the stress considered. Basalt, glass and carbon fabrics are used as reinforcement. These materials are not prone to corrosion. Therefore, the cover layer is significantly lower compared to standard reinforced concrete and very thin TRC elements can be produced. 4

The combination of grid structures with suitable mesh density and the appropriate size of grain aggregates is essential to ensure satisfactory cohesion between the fabric and the concrete. A fine-grained concrete matrix is usually used to ensure effortless casting and aesthetic quality of the surface of the reinforced element. [5] An additional surface treatment by grinding or painting is desirable for an architectural concrete. The absorbency of the final product can be greatly influenced by surface treatment.

\section{Results AND DISCUSSION}

As part of the research on this issue, testing specimens were made. A slab of $700 \mathrm{~mm}$ was selected as a reference test specimen for thin-walled structures. The thickness of the slab was reduced during the experiments $25 \mathrm{~mm}, 20 \mathrm{~mm}, 18 \mathrm{~mm}$ for technology verification of maximized lightening of construction, while maintaining sufficient load bearing capacity. A coffee table (Figure 1) was made in a vertical formwork as an example of the final product in a bachelor thesis [3].

To compare TRLC specimen behaviour, several reinforced and non-reinforced slabs and accompanying test specimens were produced to determine the strength characteristics of composite according to the standard. 2D carbon and 3D glass meshes were used for slab reinforcing (Figure 2). An overview of the slabs tested in bending is given in Table 1.

An expanded clay Liapor was used to replace natural aggregate. The maximum grain size of the porous aggregate was chosen to be $2 \mathrm{~mm}$ due to the intended application to the thin-walled elements. A bulk density of this fraction for Liapor is declared to be $575 \mathrm{~kg} / \mathrm{m}^{3}$. This reduced aggregate size also ensured sufficient co-operation with the reinforcement.

The composition used for experimental research contains cement CEM I 52.5, fine-grained sand, ash, microsilica and superplasticizer to assure a sufficiently fluid consistency of fresh concrete. For each set of specimens, the composition varied only in the watercement ratio and the amount of superplasticizer. The non-reinforced LC selected for experimental verification reaches bulk density ranging from $1,400 \mathrm{~kg} / \mathrm{m}^{3}$ to $1,600 \mathrm{~kg} / \mathrm{m}^{3}$. An average concrete compressive strength of $32,02 \mathrm{MPa}$ was proved on cube specimens with dimensions 100/100/100 mm.

The experimental research has brought some insights. Because of using the Liapor aggregate for the production of fresh concrete, it is necessary to solve the method of compaction in thin-walled slabs. The compaction on the vibratory tables produces a non-homogeneous composite. The cement stone is placed at the bottom and the Liapor aggregate at the upper surface. This phenomenon leads to a high tensile bending strength of concrete composite and consequently high load bearing capacity of the slabs during loading (Table 2). The fixing of the reinforcing mesh position appeared to be difficult. 


\begin{tabular}{|c|c|c|c|c|c|}
\hline \multirow[t]{2}{*}{ FORMWORK } & \multirow{2}{*}{$\begin{array}{l}\text { WEIGHT } \\
m[\mathrm{~kg}]\end{array}$} & \multirow{2}{*}{$\begin{array}{c}\text { BULK } \\
\text { DENSITY } \\
\rho\left[\mathrm{kg} / \mathrm{m}^{3}\right]\end{array}$} & \multicolumn{2}{|c|}{$\begin{array}{c}\text { FORCE } \\
F[\mathrm{kN}]\end{array}$} & \multirow{2}{*}{$\begin{array}{l}\text { MOMENT } \\
M_{\text {max }}[\mathrm{kNm}]\end{array}$} \\
\hline & & & $\begin{array}{c}\text { first } \\
\text { crack }\end{array}$ & $\begin{array}{l}\text { maximal } \\
\text { force }\end{array}$ & \\
\hline \multirow{2}{*}{$\begin{array}{c}\text { VERTICAL } \\
\text { HORIZONTAL }\end{array}$} & 8.02 & 1591.27 & 0.23 & 0.58 & 0.087 \\
\hline & 6.91 & 1371.03 & 0.56 & 1.8 & 0.27 \\
\hline \multirow[t]{2}{*}{ FORMWORK } & $\begin{array}{c}\text { FLEXURAL } \\
\text { STRENGTH } \\
\text { WITHOUT } \\
\text { CRACKS }\end{array}$ & \multicolumn{4}{|c|}{$\begin{array}{c}\text { DEFLECTION } \\
w[\mathrm{~mm}]\end{array}$} \\
\hline & $\sigma_{b}[\mathrm{MPa}]$ & $\begin{array}{l}\text { FIRST } \\
\text { CRACK }\end{array}$ & \multicolumn{2}{|c|}{$\begin{array}{l}\text { MAXIMAL } \\
\text { FORCE }\end{array}$} & $\begin{array}{c}\text { AFTER } \\
\text { UNLOADING }\end{array}$ \\
\hline VERTICAL & 4.03 & 1.12 & \multicolumn{2}{|c|}{18.62} & 2.6 \\
\hline HORIZONTAL & 12.5 & 1.19 & \multicolumn{2}{|c|}{41.97} & 4.3 \\
\hline
\end{tabular}

TABLE 2. Flexural test results for TRLC slabs with 3D glass textile.
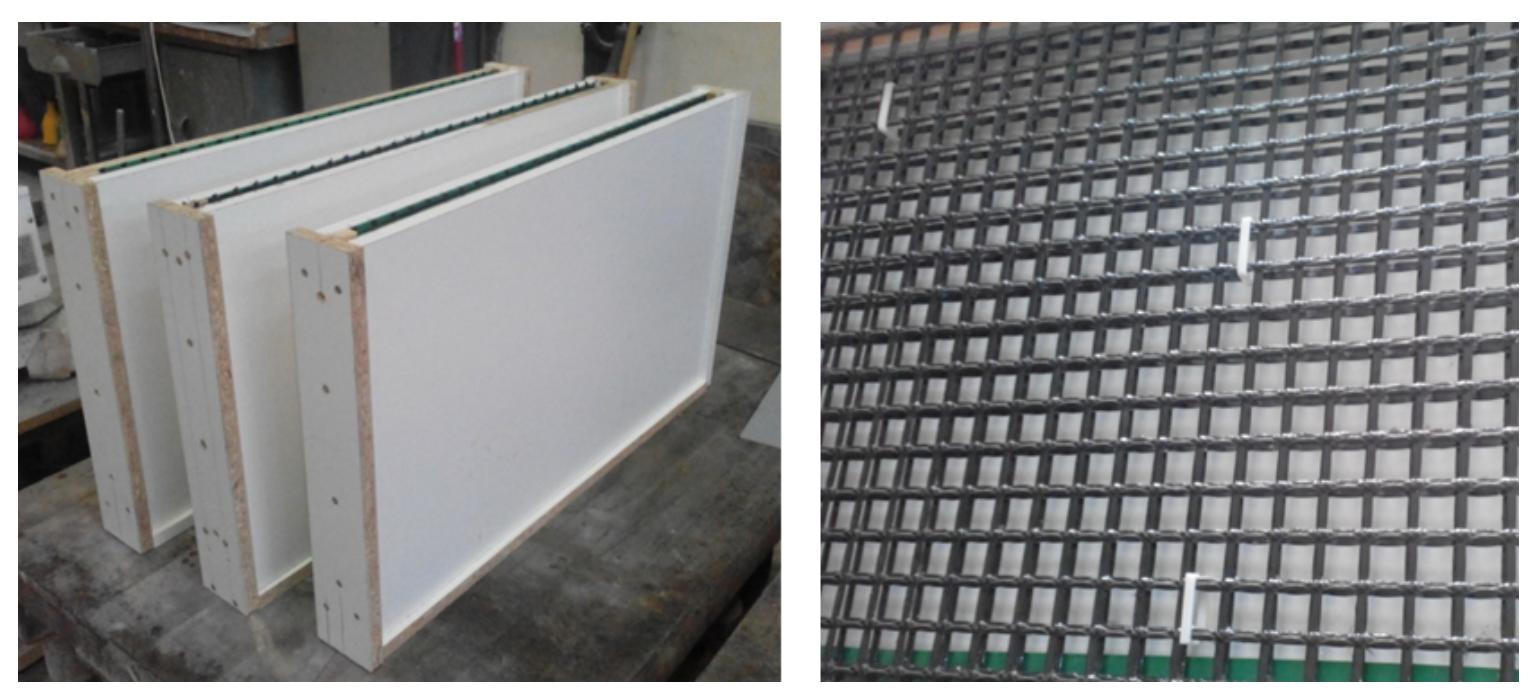

FiguRE 3. Formwork for TRLC slabs with 2D carbon textile.
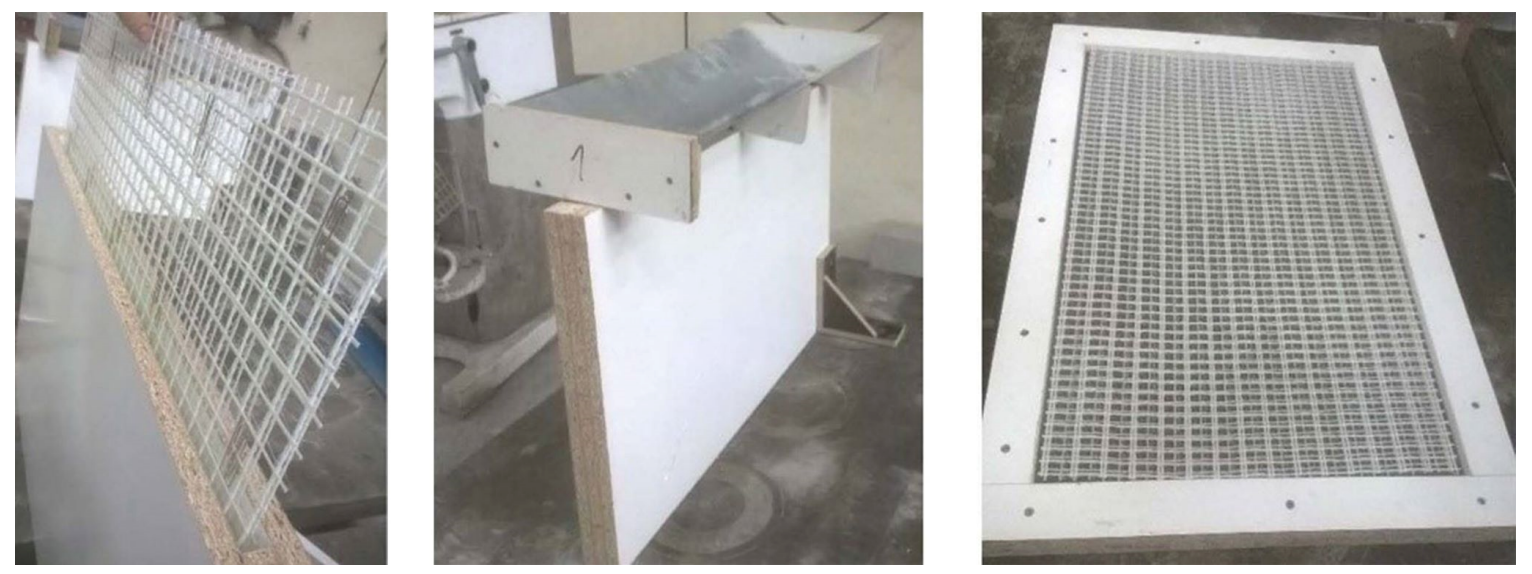

FiguRE 4. Formwork for TRLC slabs with 3D glass textile. 


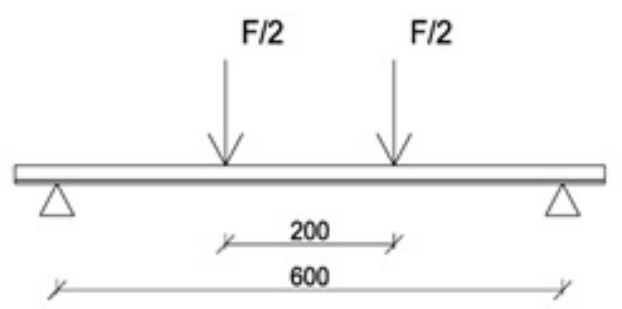

Figure 5. The static scheme of slab loading.

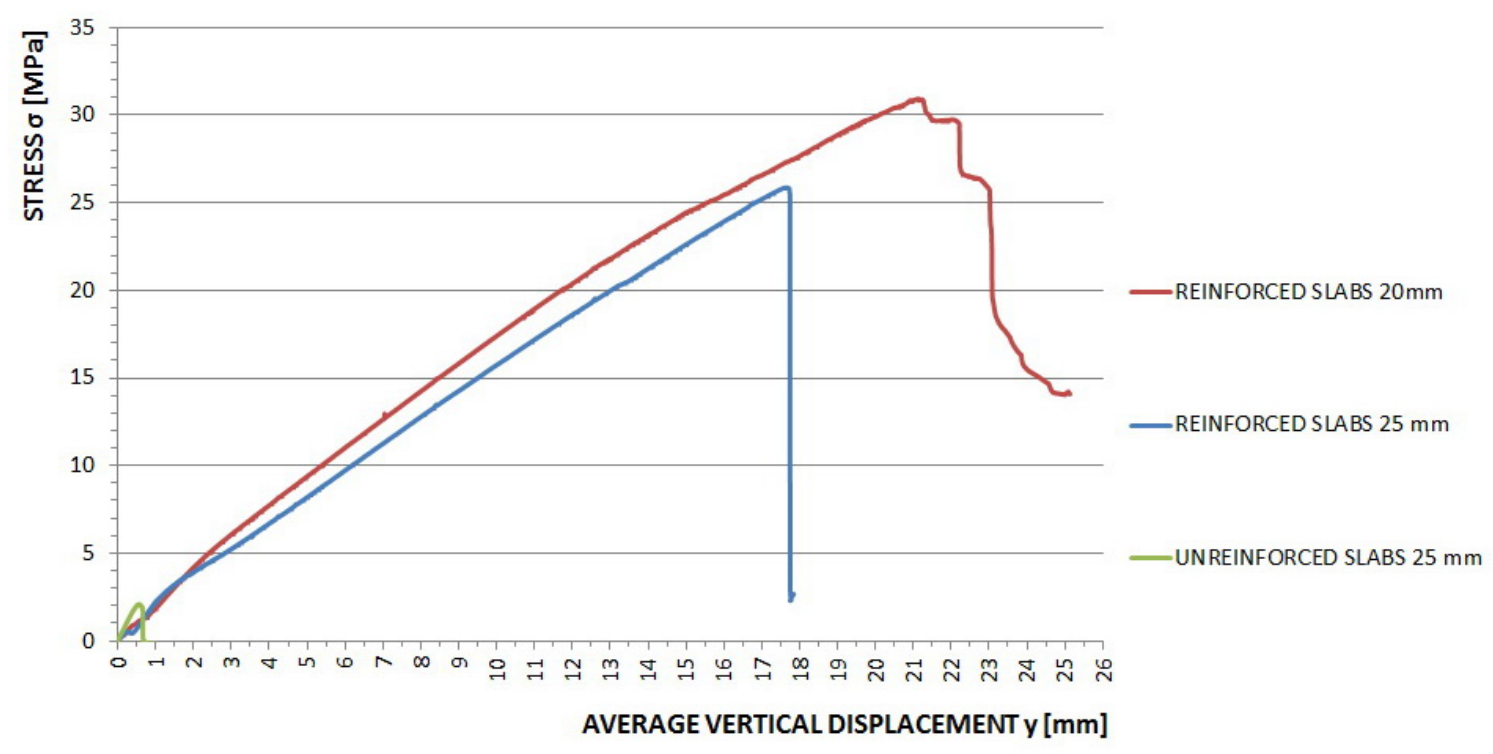

Figure 6 . The flexural testing of TRLC slabs with 2D carbon textile.

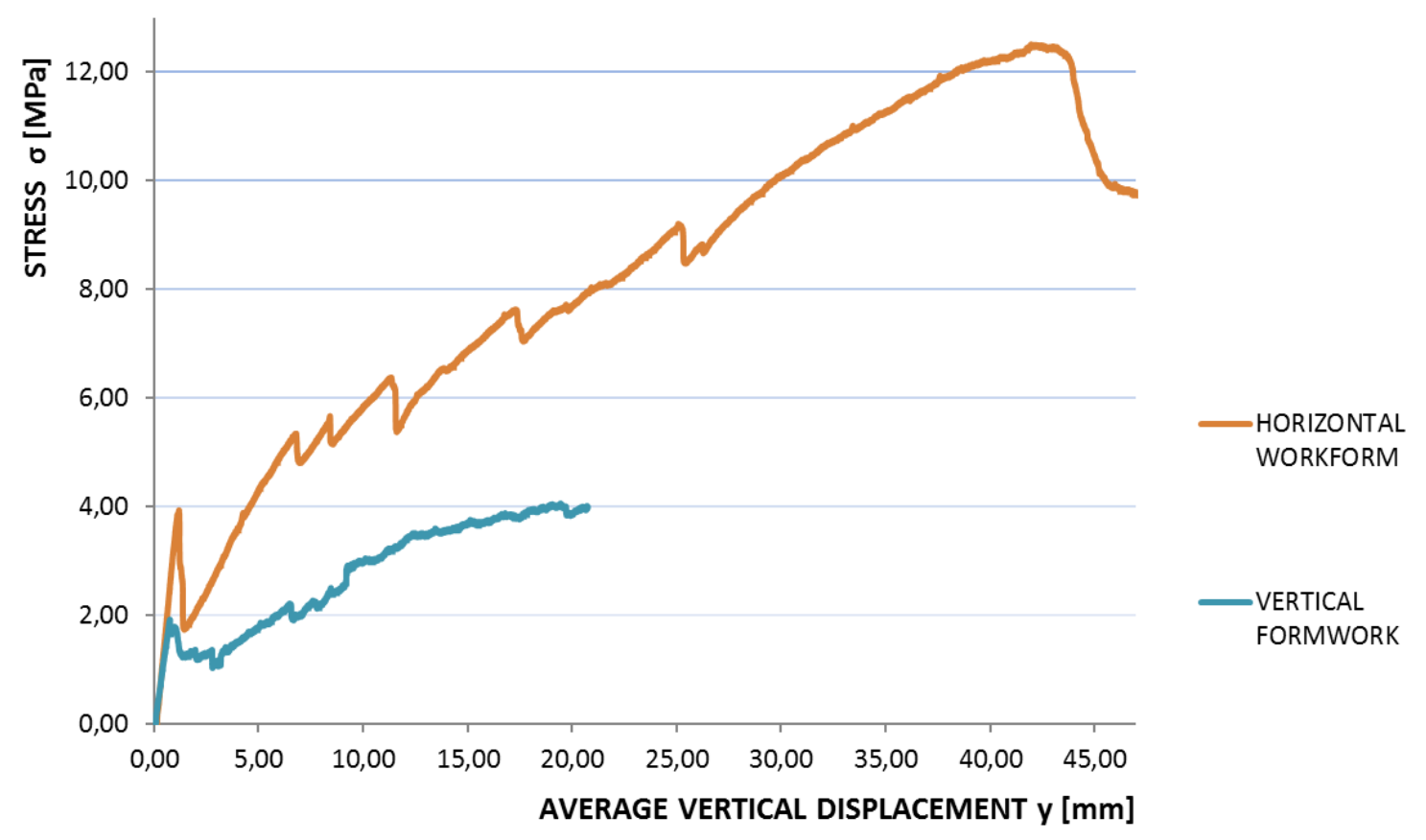

FIgURE 7 . The flexural testing of TRLC slabs with 3D glass textile. 
To eliminate both of these negative effects, the next production of the slabs was realized in a vertical position with double-sided formwork. The filling with fresh concrete was carried out by a metal funnel and the compaction was done only by tapping on the formwork walls. The fixing of the mesh was secured by clamping between the firmly bonded formwork walls (Figure 3).

\section{Conclusion}

Replacing natural aggregate by porous aggregate is one of the ways to reduce the weight of the concrete element. The lightweight concrete thus formed can be reinforced by special reinforcements, such as gridshaped fibres. By combining these approaches, it is possible to create lightweight and thin concrete elements with high load bearing capacity.

The article deals with an initial research seeking new ways for TRLC designing and casting. For the purpose of the research, several thin-walled slabs reinforced with 2D carbon and 3D glass fabrics and unreinforced specimens were produced by various casting processes to prove the material characteristics of lightweight concrete. The producing described in the article is original. No identical production was found in scientific literature.

The method of casting has a significant effect on the material characteristics of the elements. Bending tests confirmed a great increase in strength for all reinforced specimens. We decided to post the most interesting results, which are fundamental for further research - compaction in horizontal position, fixation of lightweight concrete slabs, and homogeneity of the composite. The application of TRLC to thin-walled elements is a real alternative to the present materials and technologies.

\section{ACKNOWLEDGEMENTS}

This work was supported by the Grant Agency of the Czech Technical University in Prague, grants number SGS15/036/OHK1/1T/1, SGS16/044/OHK1/1T/11, SGS17/049/OHK1/1T/11 and SGS18/115/OHK1/2T/11.

\section{REFERENCES}

[1] L. Svoboda. Building Materials. Jaga, Bratislava, 2007.

[2] M. Hubertova. Static elasticity modulus of light-weight structural concrete. In Beton TKS, vol. 4, pp. 50-53. 2010.

[3] F. Vastl. Desing of Coffee Table from Lightweight Concrete with Mesh Reinforcement. Bachelor's thesis, CTU in Prague, 2017.

[4] J. Hegger, M. Zell, M. Horstmann. Textile reinforced concrete - realization in applications. In Tailor Made Concrete Structures. London, 2008. DOI:10.1201/9781439828410

[5] S. Gelbrich, H. L. Funke, A. Ehrlich, L. Kroll. Flexible fiber-reinforced plastic formworks for the production of curved textile-reinforced concrete. Advances in Structural Engineering 21(4):580-588, 2018. DOI: $10.1177 / 1369433217732681$ 